\title{
The impacts of aerosol loading, composition, and water uptake on aerosol extinction variability in the Baltimore-Washington, D.C. region
}

\author{
A. J. Beyersdorf ${ }^{1}$, L. D. Ziemba ${ }^{1}$, G. Chen ${ }^{1}$, C. A. Corr $^{1,2}$, J. H. Crawford ${ }^{1}$, G. S. Diskin ${ }^{1}$, R. H. Moore ${ }^{1}$, \\ K. L. Thornhill ${ }^{1,3}$, E. L. Winstead ${ }^{1,3}$, and B. E. Anderson ${ }^{1}$ \\ ${ }^{1}$ NASA Langley Research Center, Hampton, Virginia, USA \\ ${ }^{2}$ Oak Ridge Associated Universities, Oak Ridge, Tennessee, USA \\ ${ }^{3}$ Science Systems and Applications, Inc., Hampton, Virginia, USA
}

Correspondence to: A. J. Beyersdorf (andreas.j.beyersdorf@nasa.gov)

Received: 5 August 2015 - Published in Atmos. Chem. Phys. Discuss.: 28 August 2015

Revised: 16 November 2015 - Accepted: 21 December 2015 - Published: 28 January 2016

\begin{abstract}
In order to utilize satellite-based aerosol measurements for the determination of air quality, the relationship between aerosol optical properties (wavelength-dependent, column-integrated extinction measured by satellites) and mass measurements of aerosol loading ( $\mathrm{PM}_{2.5}$ used for air quality monitoring) must be understood. This connection varies with many factors including those specific to the aerosol type - such as composition, size, and hygroscopicity - and to the surrounding atmosphere, such as temperature, relative humidity $(\mathrm{RH})$, and altitude, all of which can vary spatially and temporally. During the DISCOVER-AQ (Deriving Information on Surface conditions from Column and Vertically Resolved Observations Relevant to Air Quality) project, extensive in situ atmospheric profiling in the Baltimore, MD-Washington, D.C. region was performed during 14 flights in July 2011. Identical flight plans and profile locations throughout the project provide meaningful statistics for determining the variability in and correlations between aerosol loading, composition, optical properties, and meteorological conditions.

Measured water-soluble aerosol mass was composed primarily of ammonium sulfate (campaign average of $32 \%$ ) and organics $(57 \%)$. A distinct difference in composition was observed, with high-loading days having a proportionally larger percentage of sulfate due to transport from the Ohio River Valley. This composition shift caused a change in the aerosol water-uptake potential (hygroscopicity) such that higher relative contributions of inorganics increased the bulk aerosol
\end{abstract}

hygroscopicity. These days also tended to have higher relative humidity, causing an increase in the water content of the aerosol. Conversely, low-aerosol-loading days had lower sulfate and higher black carbon contributions, causing lower single-scattering albedos (SSAs). The average black carbon concentrations were $240 \mathrm{ng} \mathrm{m}^{-3}$ in the lowest $1 \mathrm{~km}$, decreasing to $35 \mathrm{ng} \mathrm{m}^{-3}$ in the free troposphere (above $3 \mathrm{~km}$ ).

Routine airborne sampling over six locations was used to evaluate the relative contributions of aerosol loading, composition, and relative humidity (the amount of water available for uptake onto aerosols) to variability in mixed-layer aerosol extinction. Aerosol loading (dry extinction) was found to be the predominant source, accounting for $88 \%$ on average of the measured spatial variability in ambient extinction, with lesser contributions from variability in relative humidity $(10 \%)$ and aerosol composition $(1.3 \%)$. On average, changes in aerosol loading also caused $82 \%$ of the diurnal variability in ambient aerosol extinction. However on days with relative humidity above $60 \%$, variability in RH was found to cause up to $62 \%$ of the spatial variability and $95 \%$ of the diurnal variability in ambient extinction.

This work shows that extinction is driven to first order by aerosol mass loadings; however, humidity-driven hydration effects play an important secondary role. This motivates combined satellite-modeling assimilation products that are able to capture these components of the aerosol optical depth (AOD)- $-\mathrm{PM}_{2.5}$ link. Conversely, aerosol hygroscopicity and SSA play a minor role in driving variations both spatially 
and throughout the day in aerosol extinction and therefore AOD. However, changes in aerosol hygroscopicity from day to day were large and could cause a bias of up to $27 \%$ if not accounted for. Thus it appears that a single daily measurement of aerosol hygroscopicity can be used for AODto- $\mathrm{PM}_{2.5}$ conversions over the study region (on the order of $1400 \mathrm{~km}^{2}$ ). This is complimentary to the results of Chu et al. (2015), who determined that the aerosol vertical distribution from "a single lidar is feasible to cover the range of $100 \mathrm{~km}$ " in the same region.

\section{Introduction}

Aerosols are detrimental to human health and are regulated as a criteria pollutant by the United States Environmental Protection Agency (EPA, 2016) and international agencies (Vahlsing and Smith, 2012), with compliance based on measurements at ground sites. However, satellites allow for the measurement of atmospheric conditions with a larger spatial coverage than possible with a ground-based network of instruments and thus have the potential to be useful tools in diagnosing ground-level air quality, particularly of aerosols (Al-Saadi et al., 2005). Additionally, satellites have the advantage of detecting regional air quality events in areas without historical air quality problems which thus have no or limited ground-based sensor stations.

In order to relate satellite aerosol measurements to surface air quality, the connection between aerosol optical depth (AOD) measured by satellites and ground-level fine-mode aerosol mass $\left(\mathrm{PM}_{2.5}\right)$ must be known. The relationship between AOD and $\mathrm{PM}_{2.5}$ has been widely studied (Hoff and Christopher, 2009, and the references therein; Crumeyrolle et al., 2014, for the current region), and ground-level $\mathrm{PM}_{2.5}$ has been estimated based on AOD measurements both empirically (Liu et al., 2005) and through the use of global models. Van Donkelaar et al. (2006) found that the relative vertical extinction profile is the most important factor in the AOD-to-PM 2.5 relationship. Thus this relationship is weakest in regions where the vertical distribution cannot be reasonably modeled and is best in regions with fairly uniform aerosol type and vertical distribution (well-mixed boundary layer with minimal free-tropospheric aerosol) such as the northeast USA (Engel-Cox et al., 2004). Based on lidar measurements in the Baltimore, MD-Washington, D.C. region, Chu et al. (2015) suggested that a single lidar could provide adequate information on the vertical distribution to allow for retrievals of $\mathrm{PM}_{2.5}$ from AOD measurements made within $100 \mathrm{~km}$ of the lidar. However, the AOD-PM 2.5 relationship is dependent not only on the aerosol vertical distribution but also on variability in aerosol composition and relative humidity (RH), both of which can be large in urban areas due to the densely located nature of local and regional sources. This work is an analysis of spatial and temporal variability in aerosol loading, composition, and RH in the Baltimore,

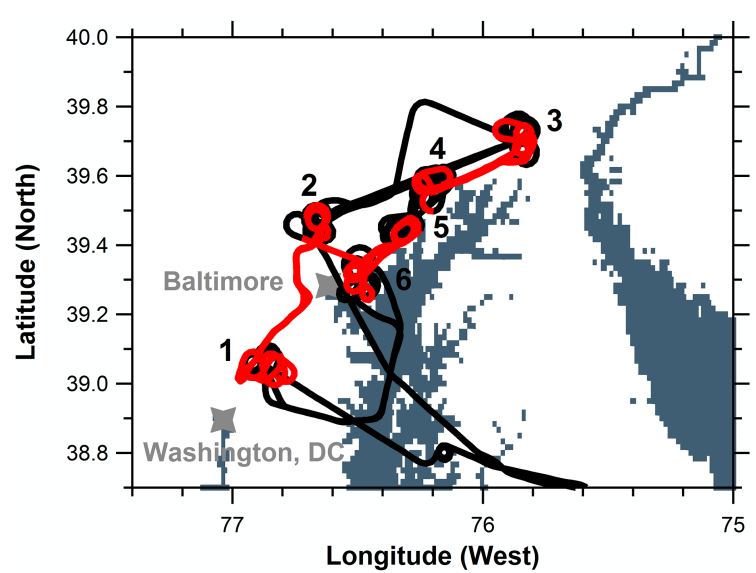

Figure 1. Flight path for flight 1 . Portions below $1 \mathrm{~km}$ are shown in red, and those above in black. Flights originated at NASA Wallops Flight Facility (southeast of the area shown) to ground sites 1 through 6 in order, with a spiral performed at each site. The circuit was typically flown three times per flight before returning to Wallops. Water is denoted as blue, with the Chesapeake Bay at the center and the Delaware Bay on the right edge.

MD-Washington, D.C. region and their effect on variability in aerosol extinction.

DISCOVER-AQ (Deriving Information on Surface conditions from Column and Vertically Resolved Observations Relevant to Air Quality) was a multi-city NASA project designed to better elucidate the connection between satellite measurements and air quality by studying the variability in gas-phase and particulate pollutants in urban environments. The first campaign was performed in the BaltimoreWashington region in July 2011 and combined remotesensing instruments on the NASA Langley UC-12 flying at $9 \mathrm{~km}$, ground-based observations at multiple sites throughout the region, and in situ airborne measurements from the NASA Wallops P-3B for the detailed analysis of atmospheric composition in the Baltimore-Washington urban airshed. The P-3B flight plans (Fig. 1) were consistent among the 14 flights over 29 days to provide meaningful statistics (Table 1).

DISCOVER-AQ provides a valuable data set to determine the variability in aerosol extinction throughout the region. However, it is important to note that changes in aerosol extinction are not necessarily solely due to an increase or decrease in aerosol loadings but can also be indicative of variability in relative humidity and aerosol composition. Thus these data will be used to examine

1. the influence that aerosol loading, composition, and relative humidity have on variability in aerosol extinction in the Baltimore-Washington region;

2. the spatial and temporal resolution requirements of these parameters necessary to reproduce the variability in aerosol extinction. 
Table 1. DISCOVER-AQ flight dates including complete circuits over all six sites flown.

\begin{tabular}{clc}
\hline Flight & Date (2011) & Circuits flown \\
\hline 1 & 1 July & 3 \\
2 & 2 July & 3 \\
3 & 5 July & 3 \\
4 & 10 July & 3 \\
5 & 11 July & 2 \\
6 & 14 July & 3 \\
7 & 16 July & 2 \\
8 & 20 July & 3 \\
9 & 21 July & 3 \\
10 & 22 July & 3 \\
11 & 26 July & 3 \\
12 & 27 July & 3 \\
13 & 28 July & 3 \\
14 & 29 July & 3 \\
\hline
\end{tabular}

These questions are relevant to scientists and policy makers seeking to assess the ability of satellite AOD retrievals to diagnose ground-level air quality.

\section{Experimental design}

The NASA P-3B was equipped with a variety of in situ aerosol and gas-phase measurements. The current analysis uses a subset of these measurements including aerosol scattering, absorption, size distribution, and composition. Air was sampled with an isokinetic inlet which efficiently collects and transmits particles with a diameter smaller than $4 \mu \mathrm{m}$ (McNaughton et al., 2007). Scattering coefficients at 450,550 , and $700 \mathrm{~nm}$ were measured with an integrating nephelometer (TSI, Inc. model 3563) and corrected for truncation errors according to Anderson and Ogren (1998), while absorption coefficients at 470,532 , and $660 \mathrm{~nm}$ were measured with a particle soot absorption photometer (PSAP, Radiance Research) and corrected for filter scattering according to Virkkula (2010). In order to calculate extinction, the measured Ångström exponent was used to adjust the scattering at 550 to $532 \mathrm{~nm}$ (Ziemba et al., 2013).

During sampling, the RH of the air is modified due to the temperature gradient between the outside and inside of the plane. This causes a change in the scattering coefficient due to the generally hygroscopic nature of aerosol. To provide a stable scattering signal, the sample is initially dried to approximately $20 \% \mathrm{RH}$ utilizing a nafion drier and then sampled with tandem nephelometers (with and without humidification) to find the dry $\left(\sigma_{\text {scat,dry }}\right.$ at a $\mathrm{RH}_{\text {dry }}$ of approximately $20 \%)$ and humidified scattering coefficients $\left(\sigma_{\text {scat,wet }}\right.$ at a $\mathrm{RH}_{\text {wet }}$ of approximately $80 \%$ ). These scattering measurements are related via a single-parameter monotonic growth curve (Gasso et al., 2000): $\sigma_{\text {scat,wet }}=\sigma_{\text {scat,dry }} \cdot\left[\frac{100-\mathrm{RH}_{\mathrm{wet}}}{100-\mathrm{RH}_{\mathrm{dry}}}\right]^{-\gamma}$,

where $\gamma$ is an experimentally determined variable of the hygroscopicity, with water uptake increasing with increasing $\gamma$. $\sigma_{\text {scat,dry }}$ was corrected to $20 \% \mathrm{RH}$ based on Eq. (1) to account for any variability in $\mathrm{RH}_{\mathrm{dry}}$. Once $\gamma$ is determined, the scattering at ambient $\mathrm{RH}\left(\sigma_{\mathrm{scat}, \mathrm{amb}}, \mathrm{RH}_{\mathrm{amb}}\right)$ is found from

$\sigma_{\text {scat }, \mathrm{amb}}=\sigma_{\text {scat,dry }} \cdot\left[\frac{100-\mathrm{RH}_{\mathrm{amb}}}{80}\right]^{-\gamma}$.

Ambient RH was calculated based on measurements of water vapor concentration by an open-path diode laser hygrometer (Diskin et al., 2002), static temperature, and pressure. Aerosol extinction at ambient RH $\left(\sigma_{\text {ext,amb }}\right)$ can then be found by summing $\sigma_{\text {scat,amb }}$ and absorption $\left(\sigma_{\text {abs }}\right)$ :

$\sigma_{\text {ext,amb }}=\sigma_{\text {scat,dry }} \cdot\left[\frac{100-\mathrm{RH}_{\mathrm{amb}}}{80}\right]^{-\gamma}+\sigma_{\text {abs }}$.

The dependence of aerosol absorption on RH is highly uncertain (Redemann et al., 2001; Mikhailov et al., 2006; Brem et al., 2012) and is therefore not incorporated but likely manifests as only a small uncertainty in total extinction due to the fact that absorption was only a minor component of extinction (4\% on average).

Ziemba et al. (2013) showed a good correlation $\left(R^{2}\right.$ of 0.88 based on comparison of 668 data points) between extinction measurements from the $\mathrm{P}-3 \mathrm{~B}$ and coincident measurements performed by a high-spectral-resolution lidar (HSRL) on the UC-12. Recent work (Brock et al., 2015a; Wagner et al., 2015) has suggested an additional model for aerosol hygroscopicity known as the kappa $\left(\kappa_{\text {ext }}\right)$ parameterization. However, these two models (based on $\gamma$ and $\kappa_{\text {ext }}$ ) are fairly consistent (scattering within 5\%) at RHs below $85 \%$, a range which comprised $96 \%$ of the data measured by the P-3B. In addition, the good agreement between HSRL and in situ data (utilizing the $\gamma$ correction scheme) suggests this is a valid model for the aerosol measured in Baltimore during DISCOVER-AQ (Ziemba et al., 2013).

Single-scattering albedo (SSA) describes the relationship between aerosol scattering and extinction:

$\mathrm{SSA}=\left(\frac{\sigma_{\text {scat }, \mathrm{dry}}}{\sigma_{\text {ext,dry }}}\right)=\left(\frac{\sigma_{\text {scat,dry }}}{\sigma_{\text {scat,dry }}+\sigma_{\text {abs }}}\right)$.

SSA can vary with RH (as scattering increases) but is here defined as the SSA under dry conditions $(20 \% \mathrm{RH})$. Thus Eq. (3) can be rewritten as

$$
\begin{aligned}
\sigma_{\text {ext,amb }}=\sigma_{\text {ext }, \mathrm{dry}} \\
\cdot\left[1+\mathrm{SSA} \cdot\left(\left[\frac{100-\mathrm{RH}_{\mathrm{amb}}}{80}\right]^{-\gamma}-1\right)\right] .
\end{aligned}
$$

Black carbon (BC) mass was measured with a Single Particle Soot Photometer (SP2, Droplet Measurement Technologies), 

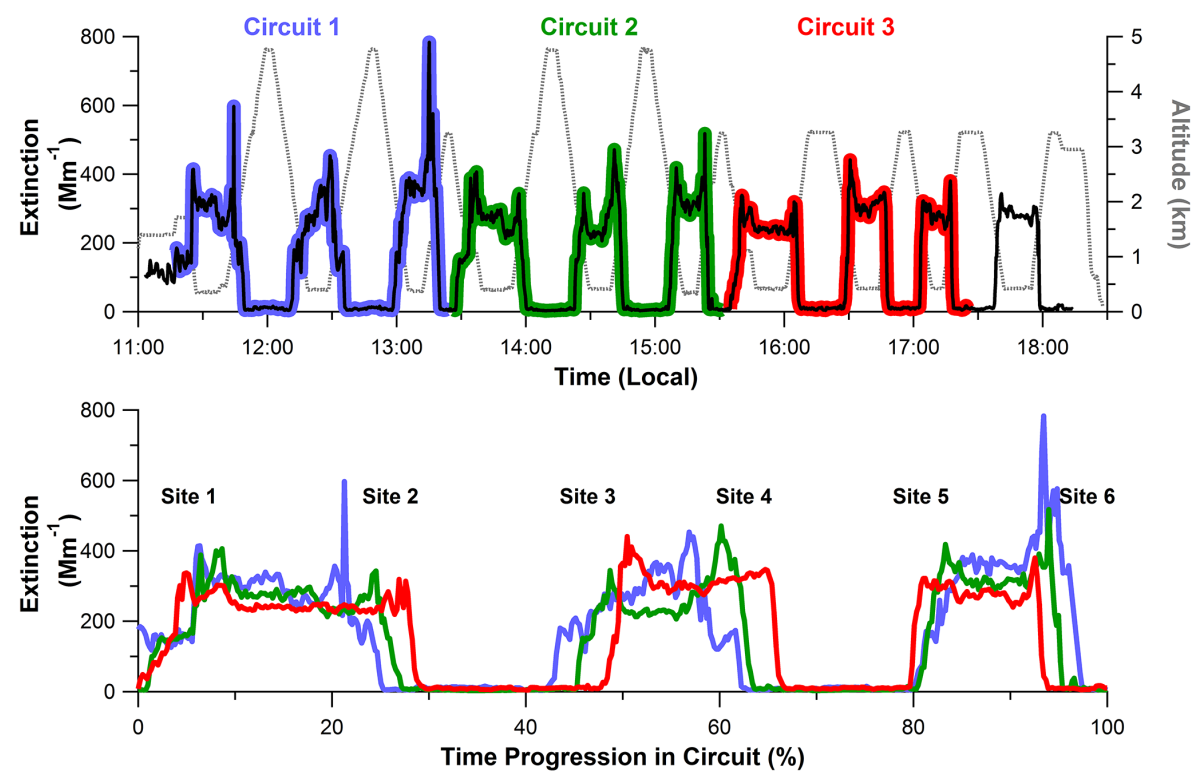

Figure 2. Time series of extinction (at ambient RH and $532 \mathrm{~nm}$ ) and altitude (gray dashed line) for flight 9 (upper panel). Extinction measurements during each circuit are highlighted by differing background color. Each circuit is then plotted in the bottom panel to show the changes in aerosol between the circuits. Profile locations correspond to those shown in Fig. 1.

while a pair of Particle-Into-Liquid Samplers (PILS, Brechtel Manufacturing, Inc.; Weber et al., 2001) were used to measure water-soluble organic and inorganic species. The PILS captures particles in the sampled air flow into a liquid flow of deionized water. Denuders prior to the PILS removed gasphase organic compounds (parallel-plate carbon filter denuders, Sunset Laboratory, Inc.) and inorganic acids and bases (annular denuders coated with sodium carbonate and phosphoric acid, URG Corporation). Laboratory testing prior to the campaign showed the use of denuders resulted in a size cut of approximately 2 microns for the PILS systems.

The first PILS was coupled to a total organic carbon (TOC) analyzer (Sievers Model 800) to give the mass of watersoluble organic carbon (WSOC) at a $10 \mathrm{~s} \mathrm{time} \mathrm{resolution.} \mathrm{The}$ TOC analyzer reports the organic carbon mass in $\mu \mathrm{gC} \mathrm{m}{ }^{-3}$ and not the total organic mass (which includes mass due to bonded hydrogen and oxygen atoms). Thus, to determine total water-soluble organic matter (WSOM), a multiplier ranging from 1.6 for urban to 2.1 for non-urban aerosols must be applied (Turpin and Lim, 2001). For the present work, a value of 1.8 is used based on Hand and Malm (2007). However, it should be noted that this does not include mass from any water-insoluble organic compounds.

The liquid flow from the second PILS was collected in vials at a resolution of 3.25 or $5 \mathrm{~min}$ for offline ion chromatographic (IC) analysis of chloride, nitrate, nitrite, sulfate, sodium, ammonium, potassium, magnesium, and calcium mass concentrations. The IC (Dionex ICS-3000 with an auto-sampler) utilized a CS12A column for cation analysis and an AS11 column for anion analysis with run times of 15 and $20 \mathrm{~min}$, respectively. Standards were run periodi- cally for calibration and to ensure system stability. Dilution was measured in the PILS through the addition of lithium bromide to its water supply. Complete inorganic composition data are not available from the first three flights due to contamination from the sample vials; alternate vials were used for the remainder of the campaign. Aerosol size distributions were measured with an Ultra-High Sensitivity Aerosol Spectrometer (UHSAS, Droplet Measurement Technologies) calibrated with ammonium sulfate. All data are publicly available from the NASA Langley Atmospheric Science Data Center (ASDC, 2015).

As the PILS is unable to measure insoluble aerosol, the measured aerosol mass is a lower limit for the actual mass. The PILS mass can be compared to the volume measured by the UHSAS utilizing a density determined based on the measured mass of organics $\left(1.2 \mathrm{~g} \mathrm{~cm}^{-3}\right.$; Turpin and Lim, 2001) and ammonium sulfate $\left(1.77 \mathrm{~g} \mathrm{~cm}^{-3}\right)$. Based on this analysis, the PILS measured approximately $82 \%$ of the aerosol mass, with the other $18 \%$ assumed to be insoluble organic compounds. Higher insoluble organic masses are estimated for higher loadings days, with insoluble loadings near zero for low-loading days. However, this analysis has a large uncertainty due to a difference in size range measured by the two instruments and volatilization of aerosol at the PILS tip. Measurements by Sorooshian et al. (2006) show that slightly more than $10 \%$ of the ammonium is lost in the PILS with a tip temperature of approximately $100^{\circ} \mathrm{C}$. Good closure (slope of 0.98 ) between cations and anions (equivalence) suggests that any loss mechanisms are equivalent for all species. Thus, while this analysis gives an approximation 

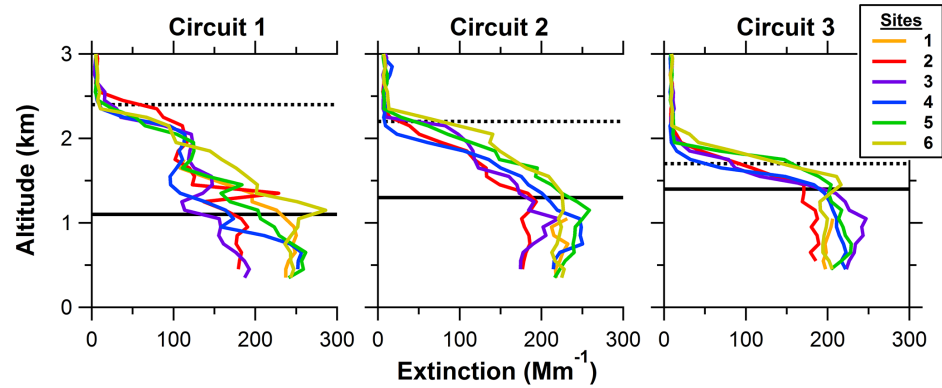

Figure 3. Vertical profiles of aerosol extinction (at ambient RH and $532 \mathrm{~nm}$ ) for flight 9 segregated by circuit and profile site. Horizontal lines represent the boundary layer (solid line) and buffer layer (dashed line) heights during each circuit at site 2 based on airborne measurements of the potential temperature profile.

of possible insoluble mass, this estimation is not included in future analysis due to the high uncertainty.

\section{Results - mission overview}

Each DISCOVER-AQ Maryland flight can be broken into two to three repetitive circuits which encompassed spirals from 0.3 to $4.5 \mathrm{~km}$ centered over six primary ground sites (labelled as sites 1-6 in Fig. 1). When time permitted, additional spirals were performed at select sites at the end of the flight, resulting in two to four spirals over each site per flight. A time series of aerosol extinction during flight 9 highlights an altitude dependence of aerosol scattering, with values oscillating between near zero in the free troposphere and greater than $200 \mathrm{Mm}^{-1}$ in the mixing layer (Fig. 2).

The repetitive flight plan allows for the analysis of differences in aerosol properties and their vertical distributions at each site as source profiles and boundary layer dynamics changed during the day, as seen for flight 9 in Fig. 3. During the first circuit (11:00-13:30 local time), a mixed layer up to $1.5 \mathrm{~km}$ is seen, capped by a residual layer between 1.5 and $2.5 \mathrm{~km}$. Surface heating causes the two layers to merge by the time the second circuit was performed (13:30-15:30), with fairly constant extinction to $1.5 \mathrm{~km}$ and a gradual decrease to near-zero extinction by $2.5 \mathrm{~km}$. Circuit 3 (15:30-17:30) had constant extinction below $1.5 \mathrm{~km}$ but little indication of a residual layer. In addition, the profiles among the sites become more homogeneous as the day progresses (Fig. 3). In general, the mixing layer was consistently greater than $1 \mathrm{~km}$ throughout the flights; therefore, data below $1 \mathrm{~km}$ are used as a measure of mixing layer aerosol properties.

Aerosol mass loadings varied by a factor of 6 (Fig. 4) between the flights, with average aerosol mass in the lowest $1 \mathrm{~km}$ ranging from 3.8 to $26 \mu \mathrm{g} \mathrm{m}^{-3}$. Aerosol optical measurements varied by an even greater amount, with ambient aerosol extinction in the lowest $1 \mathrm{~km}$ ranging from 20 to $290 \mathrm{Mm}^{-1}$ and AODs (calculated from the integration of the extinction profile) ranging from 0.05 to 0.57 . In situ AOD measurements showed good agreement (within 0.04)
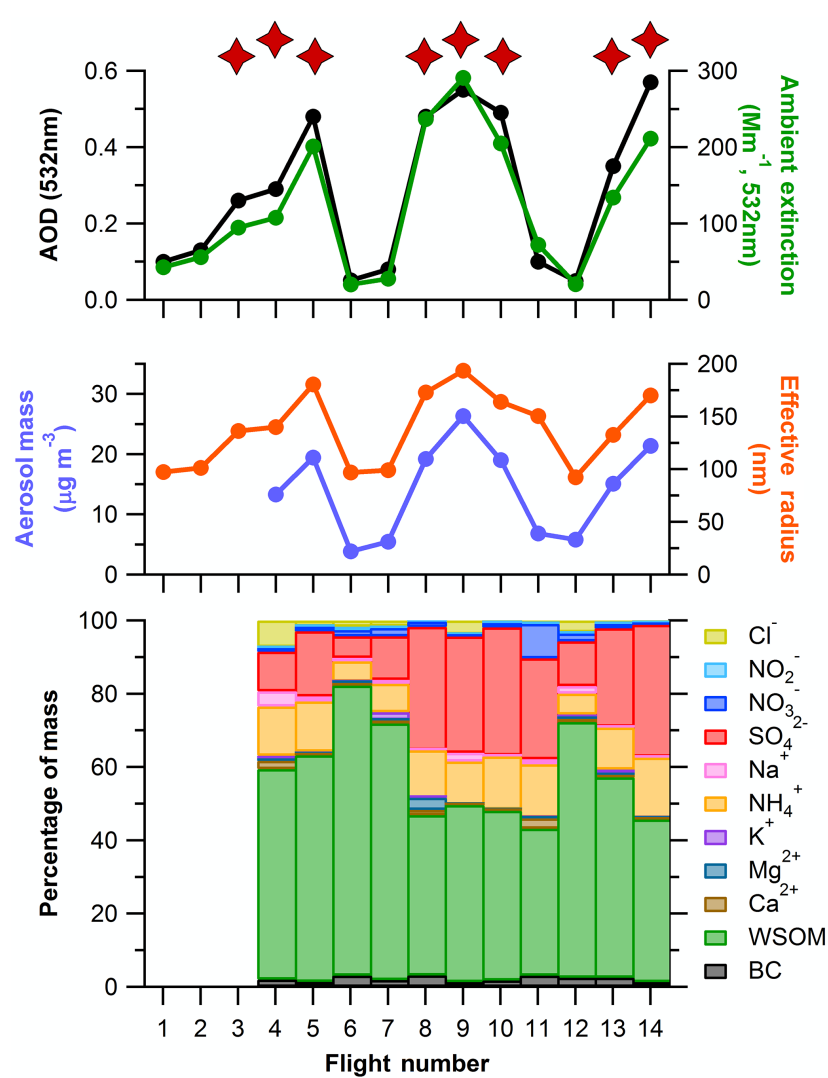

Figure 4. Average AOD (at ambient RH) along with boundary layer (below $1 \mathrm{~km}$ ) extinction, aerosol mass, effective radius, and composition for each of the 14 flights. Aerosol mass and composition data are not available for the first three flights. Flights with predominantly westerly transport from the Ohio River Valley are indicated by stars at the top of the plots.

with ground-based radiometer measurements made by the Aerosol Robotic Network (AERONET; Holben et al., 1998) in the region (L. Ziemba, personal communication, 2015). The fact that the highest extinction below $1 \mathrm{~km}$ (flight 9) and AODs (flight 14) were not measured during the same flights highlights the potential disconnect between AOD and surface 

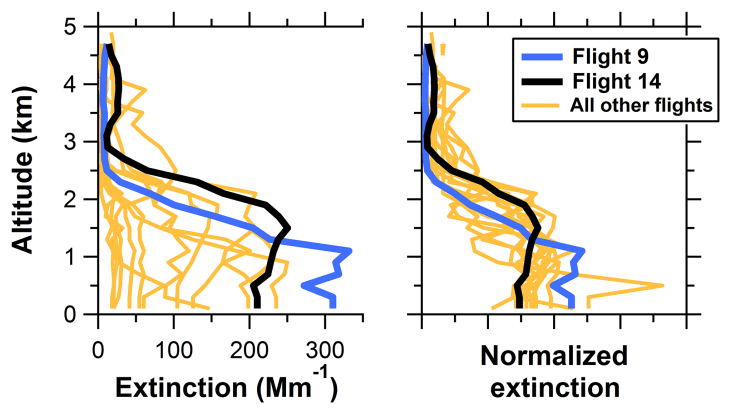

Figure 5. Average vertical profiles of aerosol extinction (at ambient RH and $532 \mathrm{~nm}$ ) for all flights, with flights 9 and 14 highlighted (left panel). These profiles can then be normalized to the total aerosol loading (AOD) to get the normalized vertical profile (right panel, arbitrary units).

layer aerosol loading. Flight 14 had a deeper aerosol layer and more aerosol in an elevated layer than flight 9 (Fig. 5); thus flight 14 had a higher AOD despite having less nearsurface extinction than flight 9 . Other surface-independent factors influencing AOD may include aerosol cloud processing. Indeed, Eck et al. (2014) observed large increases in AOD (average of $25 \%$ ) in the vicinity of non-precipitating cumulus clouds. Consistent with these findings, in situ measurements showed increases in aerosol scattering, volume, and mass in spirals measured before and after cloud formation. These included a doubling of water-soluble organics and $50 \%$ increase in sulfate.

In general, the fraction of aerosol measured was primarily a mixture of WSOM (campaign average of $57 \%$ by mass, Fig. 4), sulfate (23\%), and ammonium (10\%), with minor contributions from nitrate $(2.1 \%), \mathrm{BC}(2.2 \%)$, chloride $(2.0 \%)$, and sodium $(1.3 \%)$. The molar ratio of ammonium to sulfate was 1.92 , showing that sulfate is almost completely neutralized as ammonium sulfate, $\left(\mathrm{NH}_{4}\right)_{2} \mathrm{SO}_{4}$, with minimal bisulfate, $\left(\mathrm{NH}_{4}\right) \mathrm{HSO}_{4}$. Further, this ratio is higher (above 2) if PILS volatilization of ammonium (12\% loss of mass; Sorooshian et al., 2006) and sulfate (1\% loss) is considered. Composition varied between flights with polluted days (as noted in Fig. 4) exhibiting a higher fraction of ammonium and sulfate. Back-trajectory analysis with the Hybrid SingleParticle Lagrangian Integrated Trajectory Model (HYSPLIT; Draxler and Hess, 1998; Draxler and Rolph, 2015) suggested these high-aerosol-loading days were related to long-range transport from the Ohio River Valley (Fig. 6), which has enhanced sulfur dioxide emissions due to a high density of coalfired power plants in the region (Hand et al., 2012). These days were generally associated with low-pressure systems to the northwest of the study region. Conversely, low-loading days tended to have northerly flow due to high-pressure systems to the west.

The flights with transport from the west and higher aerosol loadings (starred in Fig. 4) were found to have relatively

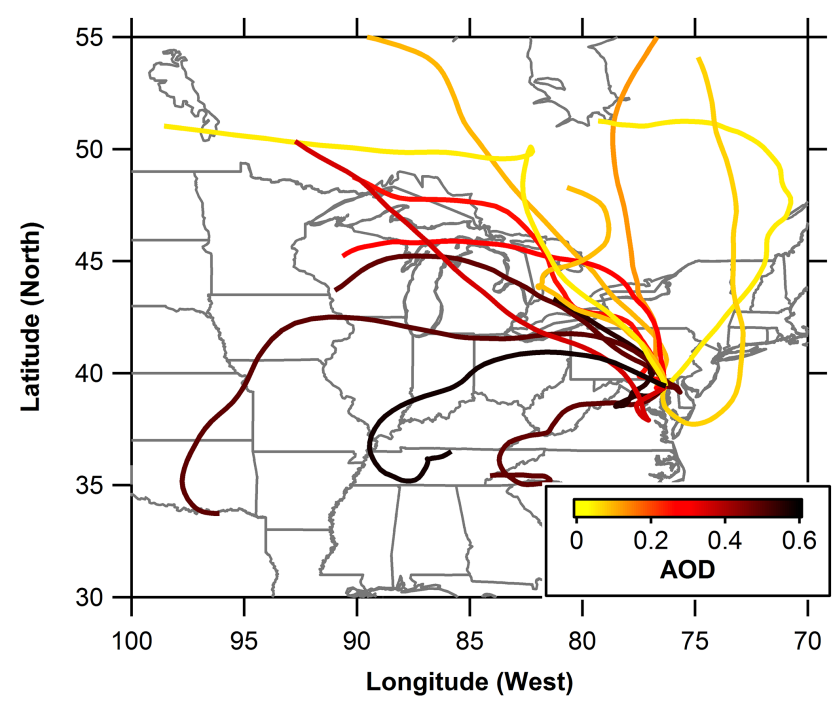

Figure 6. $72 \mathrm{~h}$ back trajectories based on HYSPLIT for the first circuit of each flight at site 5 at an altitude of $1 \mathrm{~km}$ colored by the average AOD measured during that flight.

more sulfate ( $28 \%$ of mass compared to $15 \%$ for clean days) and ammonium (polluted, $11 \%$; clean, $7.5 \%$ ) and less organics (polluted, $52 \%$; clean, $65 \%$ ). Less polluted days had higher percentages of nitrate (polluted, $1.1 \%$; clean, $3.9 \%$ ) and BC (polluted, $2.0 \%$; clean, $2.7 \%$ ). The higher BC mass percentage also leads to higher absorption relative to scattering and therefore lower SSA on these less polluted days (polluted, 0.98; clean, 0.93; Fig. 7). However, on an absolute basis the polluted days had higher $\mathrm{BC}$ and absorption than on the clean days. Average BC concentrations for the entire month were $240 \mathrm{ng} \mathrm{m}^{-3}$ in the lowest $1 \mathrm{~km}$, decreasing to $35 \mathrm{ng} \mathrm{m}^{-3}$ in the free troposphere (above $3 \mathrm{~km}$ ).

The polluted flight days also had higher $\gamma$ values (Fig. 7, Eq. 5). This water uptake is largely dependent on aerosol composition, with soluble organics having lower hygroscopicity than inorganic compounds. This can be seen as an inverse relationship with $\gamma=0.60-0.0042 \times$ organic mass fraction (Fig. 8). These values are intermediate between measurements made in other urban areas (Asia and USA - Quinn et al., 2005; Texas - Massoli et al., 2009) and in the remote atmosphere (the Indian Ocean - Quinn et al., 2005). Differences are likely due to differences in the measurement of organics; the current study uses PILS to measure only watersoluble organics, while the other studies use aerosol mass spectrometry or thermo-optical methods which are sensitive to all organic species. In addition to an elevated $\gamma$, highloading days were typically more humid ( $64 \pm 7 \%$ compared to $49 \pm 7 \%$ ). These higher humidities and $\gamma$ values resulted in a higher water content of the aerosols as evident from ambient extinctions that were $25 \%$ higher than dry values on high-loading days compared to the $12 \%$ observed on low- 

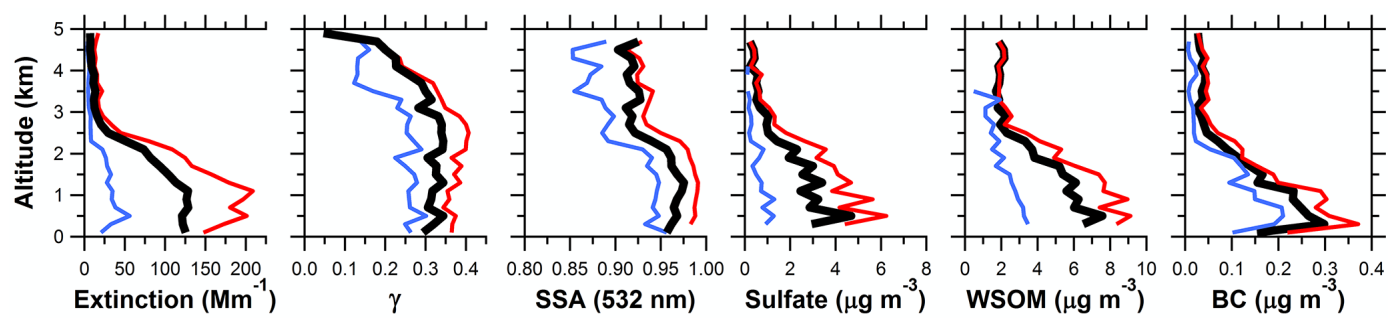

Figure 7. Average profiles for extinction (at ambient RH and $532 \mathrm{~nm}$ ), $\gamma$, SSA, and composition for all flights (black line), days with predominantly westerly transport from the Ohio River Valley (red line), and days with northerly transport (blue line).

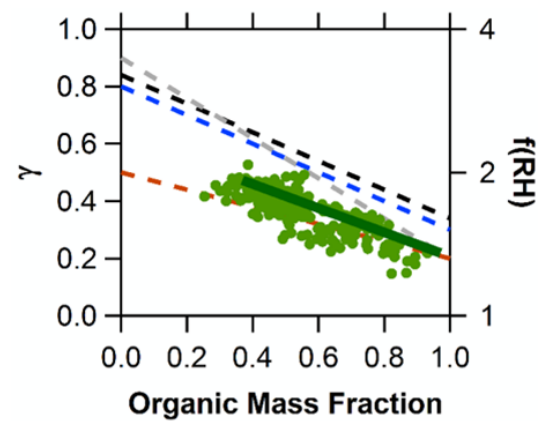

\begin{tabular}{|c|c|c|}
\hline & Slope & Y-Intercept \\
\hline Baltimore & -0.42 & 0.60 \\
Texas & -0.5 & 0.84 \\
Western Pacific & -0.7 & 0.9 \\
Northeast USA & -0.5 & 0.8 \\
Indian Ocean & -0.3 & 0.5 \\
\hline
\end{tabular}

Figure 8. Relationship between $\gamma$ (at $532 \mathrm{~nm}$ ) and organic mass fraction for the present study (data below $1 \mathrm{~km}$ ), Texas (Massoli et al., 2009), the western Pacific, the northeast USA, and the Indian Ocean (Quinn et al., 2005). The organic mass fraction is found by dividing the WSOM by the total mass measured by the PILS and SP2. Other studies used organic mass measured by aerosol mass spectrometer or thermo-optical methods. The ratio of scattering at $80 \% \mathrm{RH}$ to $20 \%[f(\mathrm{RH})]$ is shown on the right $y$ axis (note the irregular spacing).

loading days. The highest daily-averaged water content of aerosol extinction was $40 \%$ measured during flight 8 .

Aerosol mass is the primary measurement of aerosol loading and the basis on which ground air quality is regulated. Boundary layer dry extinction, ambient extinction, and AOD are additional measures of aerosol loading but incorporate an increasing amount of confounding factors. For instance, dry extinction is dependent on the aerosol mass loading in addition to aerosol size and composition. Ambient extinction is dependent on these same factors plus the aerosol hygroscopicity and RH. Finally, AOD is also dependent on the vertical distribution of aerosols and RH. Aerosol mass loading, dry extinction (not shown), ambient extinction, and AOD follow similar trends (Fig. 4), suggesting that aerosol mass loadings are the primary factor controlling day-to-day variability in aerosol optical properties. However, aerosol mass measurements via PILS do not account for insoluble aerosol. Dry mass extinction efficiencies calculated from extinction and mass measurements were variable, ranging between 3.2 and $8.3 \mathrm{~m}^{2} \mathrm{~g}^{-1}$. The highest mass extinction efficiencies (measured on high-loading days) likely are indicative of the presence of insoluble organic material. Therefore, because of the variable quantity of insoluble mass and the low time resolution of the PILS measurements, future analysis will use the dry extinction as a proxy for aerosol loadings.

\section{Results - regional variability}

Aerosol extinction varied not only on a temporal basis (Fig. 4) but also spatially. Because there is such a large difference in aerosol loadings, optical properties (related to composition), and RH between flights, using campaign averages would distort the spatial trends. Therefore, each circuit consisting of spirals over six ground sites is treated as a separate "snapshot" of the region, and the properties measured over each site are normalized to the circuit average to study the spatial variability. Data below $1 \mathrm{~km}$ pressure altitude were used from 34 circuits for which spirals were performed over all six sites (absorption measurements were not available for one additional circuit, and therefore it was not included in this analysis).

In order to get a general overview of aerosol variability in the regional, the average normalized dry and ambient extinctions along with RH for all of the circuits are shown in Fig. 9. The data are first normalized to the average for the circuit, and then the normalized values are averaged. The highest dry aerosol extinction was nearest downtown Baltimore, with site 5 extinction $5.6 \%$ larger than the average. However, the average ambient extinction measured was highest at the north end of the region where site 3 is $5.5 \%$ larger. This is consistent with the observed latitudinal gradient in RH. This shows that meteorological conditions ( $\mathrm{RH})$ can alter spatial trends in ambient extinction. Theoretically, it is possible for the entire region to have the same aerosol loading but differing extinction due to variability in composition and RH. Conversely, it is possible that the entire region could have a gradient in aerosol loading yet the composition and RH vary 

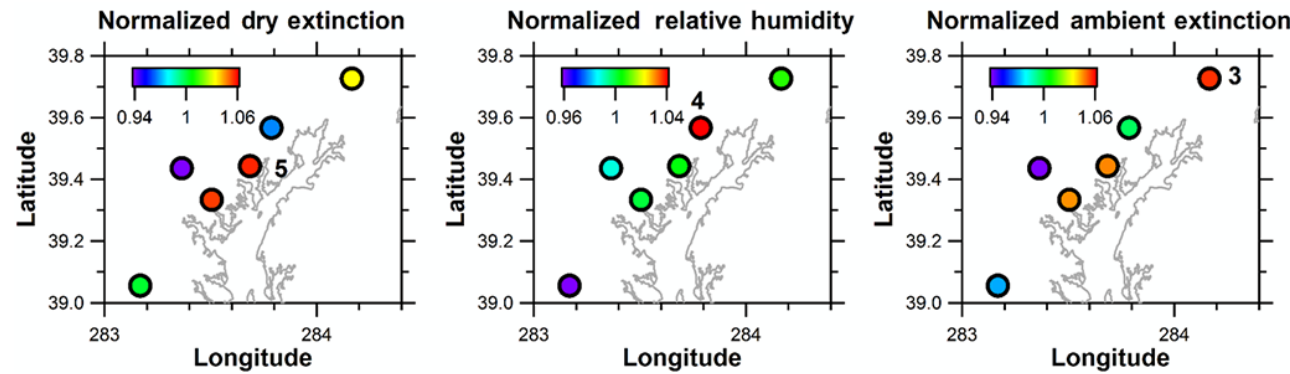

Figure 9. Average normalized $532 \mathrm{~nm}$ dry extinction (left panel), RH (center), and $532 \mathrm{~nm}$ ambient extinction (right) for all of the circuits (data are normalized to the average value for that circuit). The site with the maximum value is labelled.

in such a way that extinction is constant throughout the region.

However, in order to study aerosol variability, it is important to analyze each circuit individually (and not as a campaign average as done in Fig. 9). Equation (5) shows the dependence of aerosol ambient extinction on aerosol loading ( $\left.\sigma_{\text {ext,dry }}\right)$, composition (SSA and $\gamma$ ), and $\mathrm{RH}$, and it can be used as a simple model to determine the factors controlling aerosol ambient extinction. From this, an assessment of the accuracy needed for each of these parameters to relate aerosol extinction (which can be derived from satellite measurements) to aerosol loading can be performed. In order to determine the relative importance of aerosol loading, composition, and RH on extinction, the partial derivatives of Eq. (5) can be determined:

$$
\begin{aligned}
\frac{\partial \sigma_{\text {ext,amb }}}{\partial \sigma_{\text {ext,dry }}} & =1+\mathrm{SSA} \cdot\left(\left[\frac{100-\mathrm{RH}_{\mathrm{amb}}}{80}\right]^{-\gamma}-1\right), \\
\frac{\partial \sigma_{\mathrm{ext}, \mathrm{amb}}}{\partial \mathrm{SSA}} & =\sigma_{\mathrm{ext}, \mathrm{dry}} \cdot\left(\left[\frac{100-\mathrm{RH}_{\mathrm{amb}}}{80}\right]^{-\gamma}-1\right), \\
\frac{\partial \sigma_{\mathrm{ext}, \mathrm{amb}}}{\partial \mathrm{RH}} & =\frac{\sigma_{\mathrm{ext}, \mathrm{dry}} \cdot \mathrm{SSA} \cdot \gamma}{80}\left[\frac{100-\mathrm{RH}_{\mathrm{amb}}}{80}\right]^{-\gamma-1}, \\
\frac{\partial \sigma_{\mathrm{ext}, \mathrm{amb}}}{\partial \gamma} & =-\sigma_{\mathrm{ext}, \mathrm{dry}} \cdot \mathrm{SSA} \cdot\left[\frac{100-\mathrm{RH}_{\mathrm{amb}}}{80}\right]^{-\gamma} \\
& \cdot \ln \left(\frac{100-\mathrm{RH}_{\mathrm{amb}}}{80}\right) .
\end{aligned}
$$

As expected, ambient extinction is linear with dry extinction (the partial derivative does not contain $\sigma_{\text {ext,dry }}$ ). The positive linear dependence on SSA shows that, if all other variables are held constant, as SSA increases scattering becomes a larger fraction of extinction and at any RH above $20 \%$ will cause an increase in extinction due to water uptake. The dependence on RH and $\gamma$ are both nonlinear, and thus their effects are most important when the RH is high or the aerosol is very hygroscopic.
Flight 1, Circuit 3

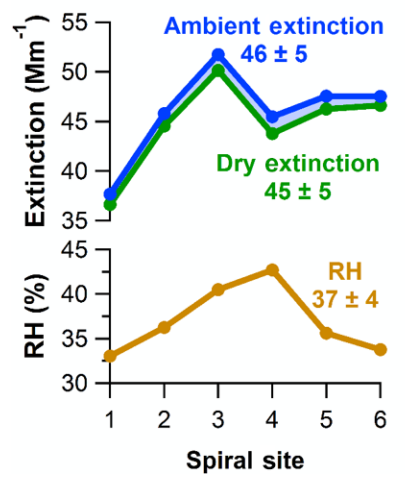

Flight 14, Circuit 1

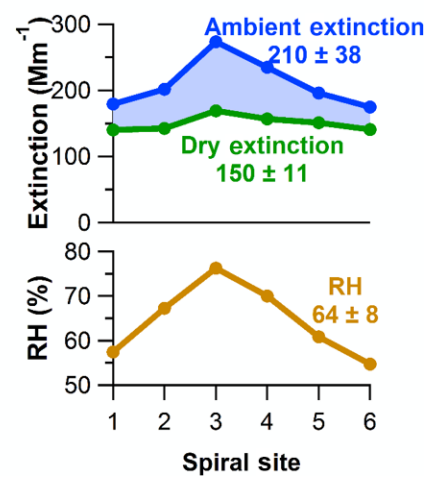

Figure 10. Average $532 \mathrm{~nm}$ ambient extinction, dry extinction, and RH below $1 \mathrm{~km}$ during spirals over the six sites during flights 1 and 14.

Equations (6) through (9) can be combined to give the total differential for $\sigma_{\text {ext,amb: }}$

$$
\begin{aligned}
\mathrm{d} \sigma_{\text {ext,amb }} & =\frac{\partial \sigma_{\text {ext,amb }}}{\partial \sigma_{\text {ext,dry }}} \cdot \mathrm{d} \sigma_{\text {ext,dry }}+\frac{\partial \sigma_{\text {ext,amb }}}{\partial \mathrm{SSA}} \cdot \mathrm{dSSA} \\
& +\frac{\partial \sigma_{\text {ext,amb }}}{\partial \mathrm{RH}} \cdot \mathrm{dRH}+\frac{\partial \sigma_{\text {ext,amb }}}{\partial \gamma} \cdot \mathrm{d} \gamma .
\end{aligned}
$$

Assuming that the four variables are independent,

$$
s\left(\sigma_{\text {ext,amb }}\right)=\left[\begin{array}{c}
\left(\frac{\partial \sigma_{\text {ext,amb }}}{\partial \sigma_{\text {ext,dry }}} \cdot s\left(\sigma_{\text {ext,dry }}\right)\right)^{2} \\
+\left(\frac{\partial \sigma_{\text {ext,amb }}}{\partial \mathrm{SSA}} \cdot s(\mathrm{SSA})\right)^{2} \\
+\left(\frac{\partial \sigma_{\text {ext,amb }}}{\partial \mathrm{RH}} \cdot s(\mathrm{RH})\right)^{2} \\
+\left(\frac{\partial \sigma_{\mathrm{ext}, \mathrm{amb}}}{\partial \gamma} \cdot s(\gamma)\right)^{2}
\end{array}\right]^{1 / 2},
$$

where $s(x)$ is the standard deviation in $x$, which is used as a measure of the variability in measurements made at the six sites during one circuit. Each term signifies the explained variance due to each of the four properties. Thus the relative 


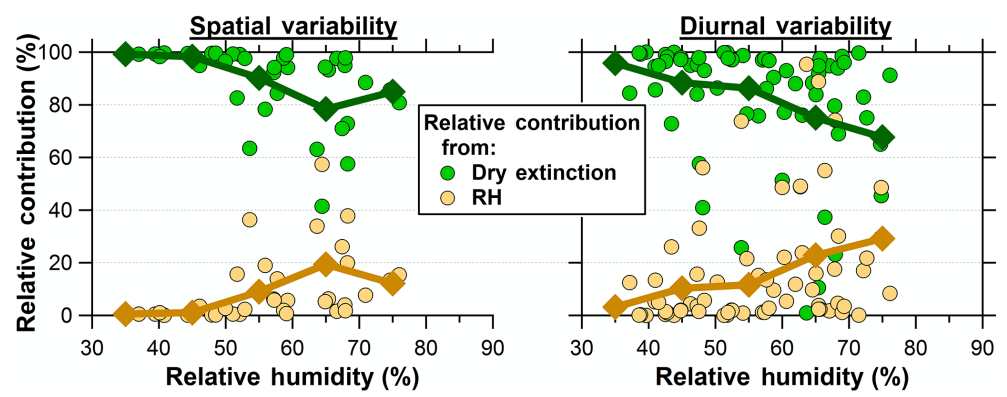

Figure 11. Relative contribution of dry extinction and RH to the spatial variability in ambient extinction as a function of RH (left) and to the diurnal variability (right). Diamonds represent the average relative contributions for $10 \% \mathrm{RH}$ increments.

Flight 1, Site 4

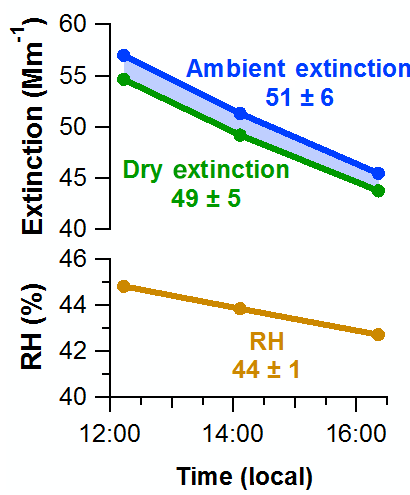

Flight 14, Site 4

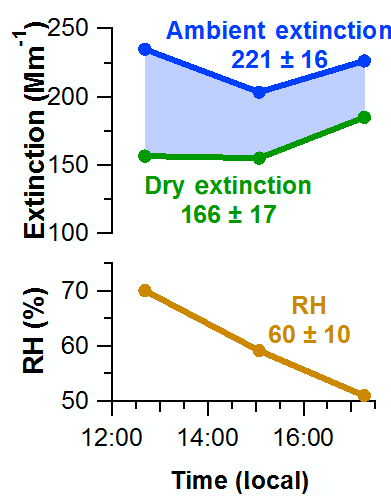

Figure 12. Trends in $532 \mathrm{~nm}$ ambient extinction, dry extinction, and RH below $1 \mathrm{~km}$ during spirals at site 4 during flights 1 and 14 .

contribution (RC) of dry aerosol scattering to the variability in ambient extinction in the region can then be found by

$\operatorname{RC}\left(\sigma_{\text {ext,dry }}\right)=\frac{\left(\frac{\partial \sigma_{\text {ext,amb }}}{\partial \sigma_{\text {ext,dry }}} \cdot s\left(\sigma_{\text {ext,dry }}\right)\right)^{2}}{s\left(\sigma_{\text {ext,amb }}\right)^{2}}$.

Using this method, the RC for each of the four variables can be determined for each circuit.

In order to determine the relative contribution of each factor to the variability in ambient aerosol extinction, each circuit was analyzed separately. Shown in Fig. 10 are two extreme cases. During flight 1 , ambient relative humidity was low $(37 \pm 4 \%)$, resulting in little water uptake (the shaded portion on the upper panel). Thus variability in dry extinction (aerosol loading) is the major contributor $\left(\operatorname{RC}\left(\sigma_{\text {ext,dry }}\right)=\right.$ $99 \%)$ to variability in ambient extinction. The second case during flight 14 shows a period of high $\mathrm{RH}(64 \pm 8 \%)$. Water uptake was substantial and greatest at site 3 , where the $\mathrm{RH}$ is the highest. In this case, the variability in aerosol extinction is dependent not only on variability in dry extinction (41\%) but also on relative humidity $(57 \%)$.

On average, aerosol loading (dry extinction) accounted for $88 \%$ of the spatial variability in extinction, with 27 of the 34 complete circuits having $\mathrm{RC}\left(\sigma_{\text {ext,dry }}\right)$ above $80 \%$ (Fig. 11$)$. Variability in RH only accounted for $10 \%$ of the ambient extinction variability on average, with only five circuits having $\mathrm{RC}(\mathrm{RH})$ greater than $20 \%$. Four of these cases where RH had a large effect on ambient extinction variability corresponded to days with high $\mathrm{RH}$ (above $60 \%$ ). This is due to the nonlinearity of extinction with respect to RH (Eq. 8). Thus at low relative humidities, changes in RH minimally impact ambient extinction. Conversely, when RHs are high, small changes can produce large variations in ambient extinction. Changes in $\gamma$ and SSA were smaller contributors to ambient extinction variability (1.3\% and less than $0.1 \%$ on average, respectively).

\section{Results - diurnal variability}

A similar analysis can be performed to examine the diurnal variability of aerosol extinction. For this analysis, each variable was averaged for each of the six sites during each flight. This produced data at each spiral site approximately every $2 \mathrm{~h}$ during each flight period (three to four values per site per day); the comparison between these values was then used to determine the diurnal variability in each parameter over the course of each flight. Sites with only two spirals during a flight were not included in this analysis. Figure 12 shows data at site 4 from the same flights used for the regional variability analysis. For flight 1, little water uptake occurred during the flight period, so more than $99 \%$ of the diurnal change in ambient extinction is due to changes in aerosol loading. In contrast, during flight 14 , extinction variability is dependent on changes both in aerosol loading and RH (51 and 49\%, respectively). From the first to second circuit, ambient extinction dropped as a result of an $\mathrm{RH}$ change from 70 to $59 \%$. After 16:00 local time, the RH continued to drop but ambient extinction increased due to an increase in dry aerosol extinction. Thus in this case, knowledge of the aerosol loading and $\mathrm{RH}$ trends are needed to interpret the aerosol extinction diurnal trends. On average, diurnal extinction variability was dominated by changing aerosol loading $(82 \%)$ with smaller contributions from changes in RH, $\gamma$, and SSA $(16,1.6$, 

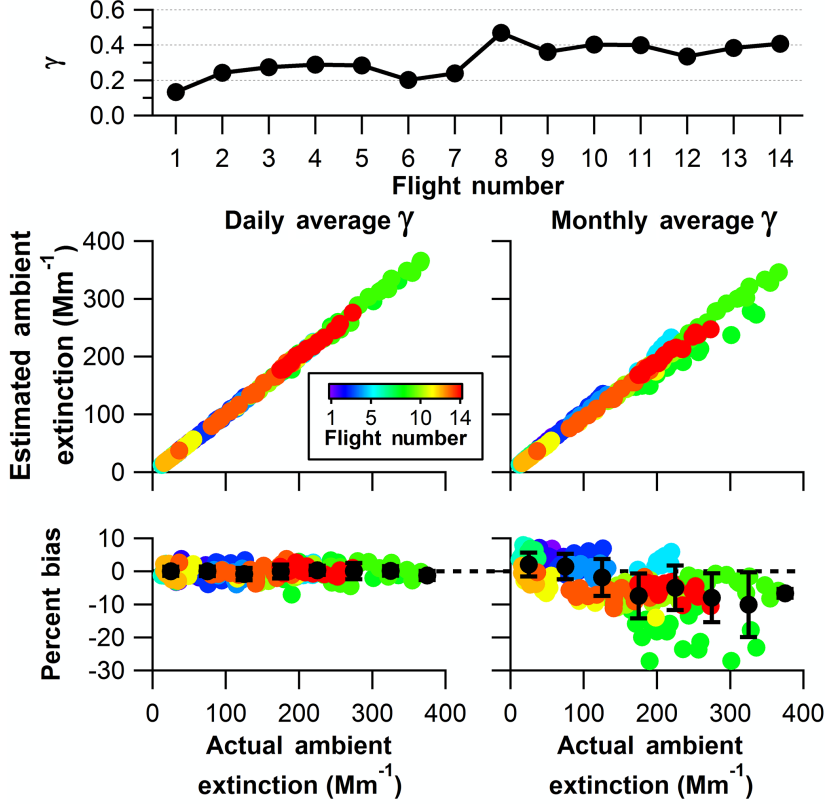

Figure 13. Average $\gamma$ for each flight (top) along with estimated ambient extinction and percent bias if the flight-average (left) and campaign-average (right) $\gamma$ are used.

and less than $0.1 \%$, respectively). However, $\mathrm{RC}(\mathrm{RH})$ values greater than $90 \%$ were measured during flight 9 (highest orange markers on the right panel of Fig. 11), a day with high $\mathrm{RH}$ and highly variable $\mathrm{RH}$.

\section{Discussion}

The conversion of extinction at ambient RH to extinction at a reduced ("dry") RH is important in relating remotesensing measurements of ambient extinction to dry aerosol mass. Though the analysis above shows that variability in $\gamma$ and SSA are only minor contributors to ambient extinction variability, converting between ambient and dry extinction requires knowledge of both parameters, as evidenced by Eq. (3). However, both $\gamma$ and SSA are not routinely measured at air quality monitoring sites. So the question could be asked, "at what frequency (both spatially and temporally) do $\gamma$ and SSA need to be known to determine the proper RH conversion?" This can be examined by analyzing the DISCOVER-AQ Maryland data recorded below $1 \mathrm{~km}$ and determining how using more averaged data yields differing ambient aerosol extinctions.

As a result of changes in composition seen in Fig. 4, $\gamma$ varied between 0.14 (flight 1 ) and 0.47 (flight 8 ), with an average of 0.32 (Fig. 13). Comparing the ambient extinction calculated during each spiral with the extinction calculated using the daily-average $\gamma$ resulted in a bias of $\pm 1.6 \%$ in ambient extinction, with no clear trend with respect to aerosol extinction. Using the monthly average for the entire region
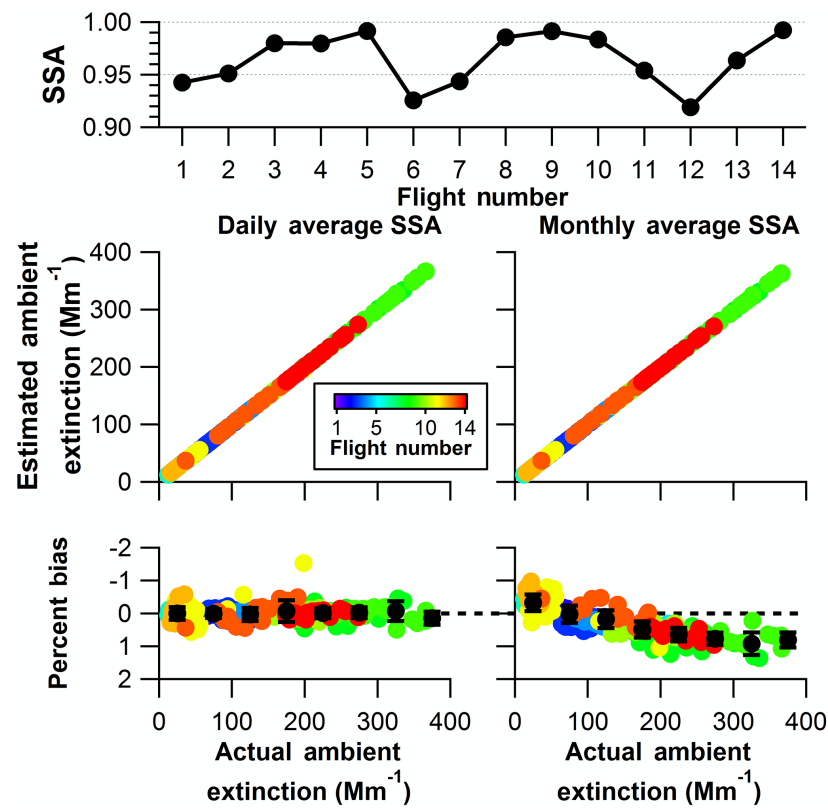

Figure 14. Average SSA for each flight (top) along with estimated ambient extinction and percent bias if the flight-average (left) and campaign-average (right) SSA are used.

Table 2. Percent bias in ambient extinction based on daily and monthly averaging of contribution variables.

\begin{tabular}{lrr}
\hline Variable & \multicolumn{2}{c}{ Percent bias } \\
& based on averaging \\
\cline { 2 - 3 } & Daily & Monthly \\
\hline Dry extinction & 22 & 111 \\
RH & 6.2 & 10.7 \\
$\gamma$ & 1.6 & 6.8 \\
SSA & 0.21 & 0.49 \\
\hline
\end{tabular}

causes a bias of $\pm 6.8 \%$ (Table 2) with deviations of up to $27 \%$ at high aerosol extinction because $\gamma$ tended to be higher on high-aerosol-loading days (Fig. 8). We conclude that spatial $\gamma$ differences in the Baltimore region are not large enough to cause significant biases in deriving dry extinction from ambient values. However, day-to-day variability in $\gamma$ can cause large discrepancies. Thus it appears that a single daily measurement of $\gamma$ (or one based on compositional measurements, Fig. 8) is able to be used for AOD-to- $\mathrm{PM}_{2.5}$ correlations over the study region (on the order of $1400 \mathrm{~km}^{2}$ ) within an uncertainty of $2 \%$.

A similar analysis can be performed to evaluate the importance of SSA in retrieving dry extinction from ambient extinction (Fig. 14 and Table 2). SSA varied from 0.91 to 0.99 during the mission with higher SSA measured on highaerosol-loading days due to the increased loading of sulfate and other secondary aerosols which are typically more scattering than primary aerosols. Comparing the ambient extinc- 

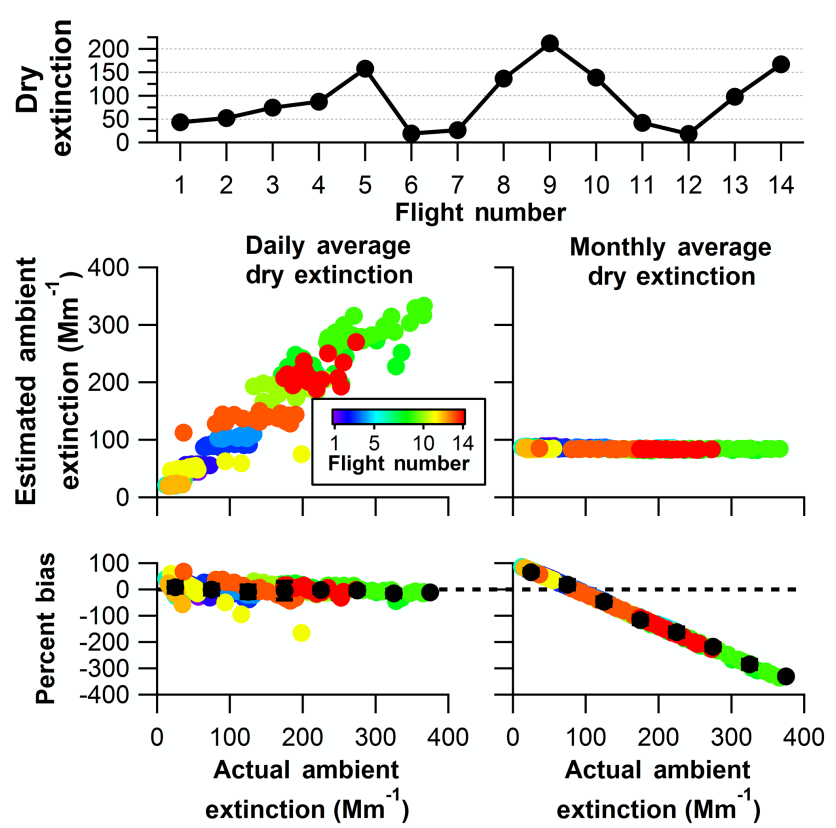

Figure 15. Average dry extinction for each flight (top) along with estimated ambient extinction and percent bias if the flight-average (left) and campaign-average (right) dry extinction are used.

tion calculated during each spiral with the extinction calculated using the daily-average SSA resulted in a bias of $\pm 0.2 \%$ in ambient extinction, showing that regional variability in SSA was not high enough to make a significant difference. Using the monthly average for the entire region produces biases of $\pm 0.5 \%$ with deviations of up to $1.0 \%$ at high aerosol extinction.

Doing the same analysis for dry aerosol extinction or RH shows markedly different results (Figs. 15 and 16, Table 2). The use of a daily-average dry extinction causes a bias of $\pm 22 \%$, showing that regional variation in aerosol loading must be accounted for. Utilizing a monthly average extinction causes discrepancies of $\pm 111 \%$ due to the large dayto-day variability in aerosol loading. Biases based on limited knowledge of RH were smaller, with $\pm 6.2 \%$ for daily and $11 \%$ for monthly RH. Thus, Table 2 gives a hierarchy of factors for variability in extinction measurements: loading $>\mathrm{RH}>\gamma>$ SSA.

An analysis of the effects of aerosol and meteorological parameters on AOD in the southeastern USA based on 37 airborne profiles (Brock et al., 2015b) shows similar trends in the significance of factors, with aerosol mass being the most important. Relative humidity had a nonlinear significance on AOD, with the greatest significance for extremely humid conditions (the 90th percentile RH profiles). Varying aerosol size parameters and the vertical distribution of the aerosols resulted in moderate AOD changes, while AODs were largely insensitive to refractive index in a fashion sim-
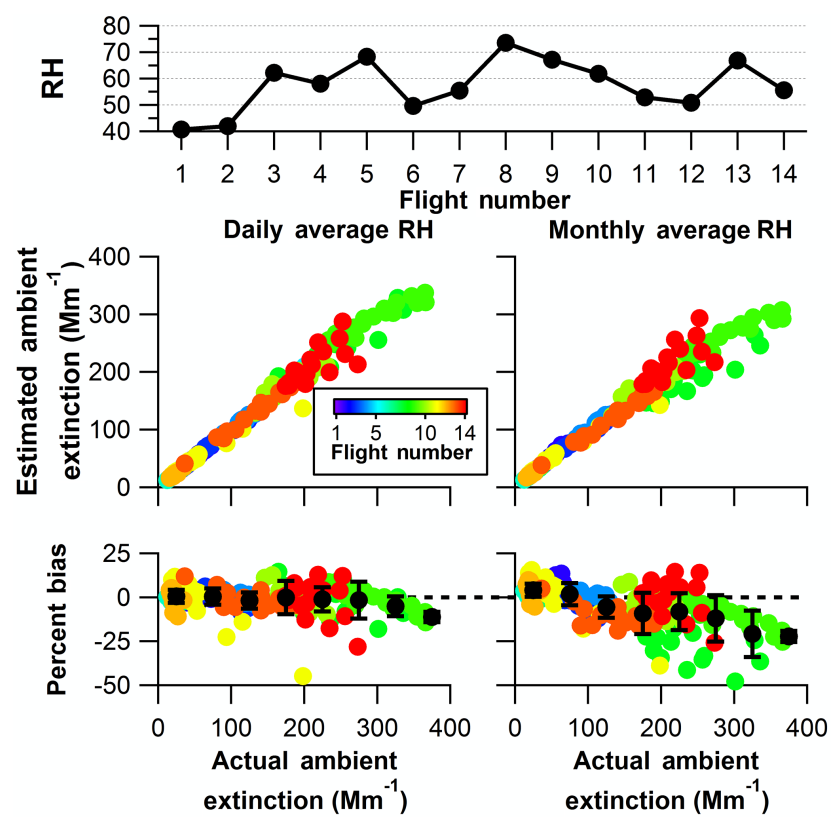

Figure 16. Average RH for each flight (top) along with estimated ambient extinction and percent bias if the flight-average (left) and campaign-average (right) $\mathrm{RH}$ are used.

ilar to the present findings of SSA as a minor contributor to extinction variability.

\section{Conclusions}

Measurements made in the Baltimore-Washington, D.C. region during DISCOVER-AQ in July 2011 can be generalized as follows: on days influenced by transport from the Ohio River Valley, aerosol loadings were higher (aerosol mass concentrations of $18.7 \pm 4.4 \mu \mathrm{g} \mathrm{m}^{-3}$ and AODs of $0.43 \pm 0.12)$ and the aerosol were more hygroscopic ( $\gamma$ of $0.36 \pm 0.07)$ because of a larger percentage of ammonium and sulfate (38\% of water-soluble mass) in comparison to days impacted by northerly transport (aerosol masses of $5.4 \pm 1.3 \mu \mathrm{g} \mathrm{m}^{-3}$, AODs of $0.08 \pm 0.03, \gamma$ of $0.26 \pm 0.09$, $20 \%$ ammonium and sulfate). In both cases, the regional and diurnal variability in aerosol extinction are controlled primarily by changes in aerosol loadings. However, on days associated with westerly transport (which also were more humid) variability in $\mathrm{RH}$ also contributed significantly to the regional $(14 \%)$ and diurnal $(22 \%)$ variability in extinction. Thus changes in AOD cannot directly be seen as changes in $\mathrm{PM}_{2.5}$ but must take into account spatial and temporal variability in RH.

Variability in aerosol composition (as indicated by $\gamma$ and SSA) was found to have a very small contribution to variability in aerosol extinction both diurnally and regionally. However, day-to-day changes in $\gamma$ were large enough that utilization of a monthly average would result in a bias of $\pm 6.8 \%$ 
in aerosol extinction with biases up to $27 \%$ for high-aerosolloading days. Thus, daily measurement of $\gamma$ (or a value derived from compositional measurements) at one location is needed to provide information for the entire study region. This is similar to the results of Chu et al. (2015) that the aerosol vertical distribution from "a single lidar is feasible to cover the range of $100 \mathrm{~km}$ " in the same region. However, this may not apply for regions outside of the US northeast which have lower AOD-to-PM 2.5 correlation because of more variable aerosol composition and vertical distributions (EngelCox et al., 2004).

Acknowledgements. This research was funded by NASA's Earth Venture-1 Program through the Earth System Science Pathfinder (ESSP) Program Office. We thank the DISCOVER-AQ Science Team, especially the pilots and flight crews of NASA's P-3B. Boundary layer heights based on airborne measurements of the potential temperature profile were provided by Don Lenschow of the University Corporation for Atmospheric Research (UCAR). Thanks also to Joshua DiGangi and Michael Shook (both of NASA Langley) for valuable discussions during manuscript preparation.

Edited by: P. DeCarlo

\section{References}

Al-Saadi, J., Szykman, J., Pierce, R. B., Kittaka, C., Neil, D., Chu, D. A., Remer, L., Gumley, L., Prins, E., Weinstock, L., MacDonald, C., Wayland, R., Dimmick, F., and Fishman, J.: Improving National Air Quality Forecasts with Satellite Aerosol Observations, B. Am. Meteorol. Soc., 86, 1249-1261, 2005.

Anderson, T. L. and Ogren, J. A.: Determining Aerosol Radiative Properties using the TSI 3563 Integrating Nephelometer, Aerosol Sci. Tech., 29, 57-69, 1998.

ASDC: NASA Airborne Science Data for Atmospheric Composition: DISCOVER-AQ, available at: http://www-air.larc.nasa. gov/cgi-bin/ArcView/discover-aq.dc-2011 (last access: 14 January 2016), 2015.

Brem, B. T., Mena Gonzalez, F. C., Meyers, S. R., Bond, T. C., and Rood, M. J.: Laboratory-Measured Optical Properties of Inorganic and Organic Aerosols at Relative Humidities up to $95 \%$, Aerosol Sci. Tech., 46, 178-190, 2012.

Brock, C. A., Wagner, N. L., Anderson, B. E., Attwood, A. R., Beyersdorf, A., Campuzano-Jost, P., Carlton, A. G., Day, D. A., Diskin, G. S., Gordon, T. D., Jimenez, J. L., Lack, D. A., Liao, J., Markovic, M. Z., Middlebrook, A. M., Ng, N. L., Perring, A. E., Richardson, M. S., Schwarz, J. P., Washenfelder, R. A., Welti, A., Xu, L., Ziemba, L. D., and Murphy, D. M.: Aerosol optical properties in the southeastern United States in summer - Part 1: Hygroscopic growth, Atmos. Chem. Phys. Discuss., 15, 2569525738, doi:10.5194/acpd-15-25695-2015, 2015a.

Brock, C. A., Wagner, N. L., Anderson, B. E., Beyersdorf, A., Campuzano-Jost, P., Day, D. A., Diskin, G. S., Gordon, T. D., Jimenez, J. L., Lack, D. A., Liao, J., Markovic, M., Middlebrook, A. M., Perring, A. E., Richardson, M. S., Schwarz, J. P., Welti, A., Ziemba, L. D., and Murphy, D. M.: Aerosol optical properties in the southeastern United States in summer - Part 2: Sensitivity of aerosol optical depth to relative humidity and aerosol parameters, Atmos. Chem. Phys. Discuss., 15, 3147131499, doi:10.5194/acpd-15-31471-2015, 2015 b.

Chu, D. A., Ferrare, R., Szykman, J., Lewis, J., Scarino, A., Hains, J., Burton, S., Chen, G., Tsaif, T., Hostetler, C., Hair, J., Holben, B., and Crawford, J.: Regional characteristics of the relationship between columnar AOD and surface $\mathrm{PM}_{2.5}$ : Application of lidar aerosol extinction profiles over Baltimore-Washington Corridor during DISCOVER-AQ, Atmos. Environ., 101, 338-349, 2015.

Crumeyrolle, S., Chen, G., Ziemba, L., Beyersdorf, A., Thornhill, L., Winstead, E., Moore, R. H., Shook, M. A., Hudgins, C., and Anderson, B. E.: Factors that influence surface $\mathrm{PM}_{2.5}$ values inferred from satellite observations: perspective gained for the US Baltimore-Washington metropolitan area during DISCOVERAQ, Atmos. Chem. Phys., 14, 2139-2153, doi:10.5194/acp-142139-2014, 2014.

Diskin, G. S., Podolske, J. R., Sachse, G. W., and Slate, T. A.: Open-path airborne tunable diode laser hygrometer, Proceedings of SPIE, 196, 4817, doi:10.1117/12.453736 2002.

Draxler, R. R. and Hess, G. D.: An overview of the HYSPLIT4 modeling system of trajectories, dispersion, and deposition, Aust. Meteorol. Mag., 47, 295-308, 1998.

Draxler, R. R. and Rolph, G. D.: NOAA Air Resources Laboratory HYSPLIT (HYbrid Single-Particle Lagrangian Integrated Trajectory), available at: http://ready.arl.noaa.gov/HYSPLIT.php (last access: 14 January 2016), 2015.

Eck, T. F., Holben, B. N., Reid, J. S., Arola, A., Ferrare, R. A., Hostetler, C. A., Crumeyrolle, S. N., Berkoff, T. A., Welton, E. J., Lolli, S., Lyapustin, A., Wang, Y., Schafer, J. S., Giles, D. M., Anderson, B. E., Thornhill, K. L., Minnis, P., Pickering, K. E., Loughner, C. P., Smirnov, A., and Sinyuk, A.: Observations of rapid aerosol optical depth enhancements in the vicinity of polluted cumulus clouds, Atmos. Chem. Phys., 14, 11633-11656, doi:10.5194/acp-14-11633-2014, 2014.

Engel-Cox, J. A., Holloman, C. H., Coutant, B. W., and Hoff, R. M.: Qualitative and quantitative evaluation of MODIS satellite sensor data for regional and urban scale air quality, Atmos. Environ., 38, 2495-2509, 2004.

EPA: National Ambient Air Quality Standards, available at: http://www3.epa.gov/ttn/naaqs/criteria.html, last access: 14 January 2016.

Gasso, S., Hegg, D. A., Covert, D. S., Collins, D., Noone, K. J., Ostrom, E., Schmid, B., Russell, P. B., Livingston, J. M., Durkee, P. A., and Jonsson, H.: Influence of humidity on the aerosol scattering coefficient and its effect on the upwelling radiance during ACE-2, Tellus B, 52, 546-567, 2000.

Hand, J. L. and Malm, W. C.: Review of aerosol mass scattering efficiencies from ground-based measurements since 1990, J. Geophys. Res., 112, D16203, doi:10.1029/2007JD008484, 2007.

Hand, J. L., Schichtel, B. A., Malm, W. C., and Pitchford, M. L.: Particulate sulfate ion concentration and $\mathrm{SO}_{2}$ emission trends in the United States from the early 1990s through 2010, Atmos. Chem. Phys., 12, 10353-10365, doi:10.5194/acp-1210353-2012, 2012.

Hoff, R. M. and Christopher, S. A.: Remote Sensing of Particulate Pollution from Space: Have We Reached the Promised Land?, J. Air Waste Manage., 59, 645-675, 2009. 
Holben, B. N., Eck, T. F., Slutsker, I., Tanre, D., Buis, J. P., Setzer, A., Vermote, E., Reagan, J. A., Kaufman, Y., Nakajima, T., Lavenu, F., Jankowiak, I., and Smirnov, A.: AERONET-A federated instrument network and data archive for aerosol characterization, Remote Sens. Environ., 66, 1-16, 1998.

Liu, Y., Sarnat, J. A., Kilaru, V., Jacob, D. J., and Koutrakis, P.: Estimating Ground-Level $\mathrm{PM}_{2.5}$ in the Eastern United States Using Satellite Remote Sensing, Environ. Sci. Technol., 39, 32693278, 2005.

Massoli, P., Bates, T. S., Quinn, P. K., Lack, D. A., Baynard, T., Lerner, B. M., Tucker, S. C., Brioude, J., Stohl, A., and Williams, E. J.: Aerosol optical and hygroscopic properties during TexAQS-GoMACCS 2006 and their impact on aerosol direct radiative forcing, J. Geophys. Res., 114, D00F07, doi:10.1029/2008JD011604, 2009.

McNaughton, C. S., Clarke, A. D., Howell, S. G., Pinkerton, M., Anderson, B., Thornhill, L., Hudgins, C., Winstead, E., Dibb, J. E., Scheuer, E., and Maring, H.: Results from the DC-8 Inlet Characterization Experiment (DICE): Airborne Versus Surface Sampling of Mineral Dust and Sea Salt Aerosols, Aerosol Sci. Tech., 41, 136-159, 2007.

Mikhailov, E. F., Vlasenko, S. S., Podgorny, I. A., Ramanathan, V., and Corrigan, C. E.: Optical properties of soot-water drop agglomerates: An experimental study, J. Geophys. Res., 111, D07209, doi:10.1029/2005JD006389, 2006.

Quinn, P. K., Bates, T. S., Baynard, T., Clarke, A. D., Onasch, T. B., Wang, W., Rood, M. J., Andrews, E., Allan, J., Carrico, C. M., Coffman, D., and Worsnop, D.: Impact of particulate organic matter on the relative humidity dependence of light scattering: A simplified parameterization, Geophys. Res. Lett., 32, L22809, doi:10.1029/2005GL024322, 2005.

Redemann, J., Russell, P. B., and Hamill, P.: Dependence of Aerosol Light Absorption and Single-Scattering Albedo on Ambient Relative Humidity for Sulfate Aerosols with Black Carbon Cores, J. Geophys. Res., 106, 27485-27495, 2001.

Sorooshian, A., Brechtel, F. J., Ma, Y. L., Weber, R. J., Corless, A., Flagan, R. C., and Seinfeld, J. H.: Modeling and characterization of a particle-into-liquid sampler (PILS), Aerosol Sci. Tech., 40, 396-409, 2006.
Turpin, B. J. and Lim, H.-J.: Species Contributions to PM $_{2.5}$ Mass Concentrations: Revisiting Common Assumptions for Estimating Organic Mass, Aerosol Sci. Tech., 35, 602-610, 2001.

Vahlsing, C. and Smith, K. R.: Global review of national ambient air quality standards for $\mathrm{PM}_{10}$ and $\mathrm{SO}_{2}(24 \mathrm{~h})$, Air Quality, Atmosphere \& Health, 5, 393-399, 2012.

van Donkelaar, A., Martin, R. V., and Rokjin, J. P.: Estimating ground-level $\mathrm{PM}_{2.5}$ using aerosol optical depth determined from satellite remote sensing, J. Geophys. Res., 111, D21201, doi:10.1029/2005JD006996, 2006.

Virkkula, A.: Correction of the calibration of the 3-wavelength Particle Soot Absorption Photometer ( $3 \lambda$ PSAP), Aerosol Sci. Tech., 44, 706-712, 2010.

Wagner, N. L., Brock, C. A., Angevine, W. M., Beyersdorf, A., Campuzano-Jost, P., Day, D., de Gouw, J. A., Diskin, G. S., Gordon, T. D., Graus, M. G., Holloway, J. S., Huey, G., Jimenez, J. L., Lack, D. A., Liao, J., Liu, X., Markovic, M. Z., Middlebrook, A. M., Mikoviny, T., Peischl, J., Perring, A. E., Richardson, M. S., Ryerson, T. B., Schwarz, J. P., Warneke, C., Welti, A., Wisthaler, A., Ziemba, L. D., and Murphy, D. M.: In situ vertical profiles of aerosol extinction, mass, and composition over the southeast United States during SENEX and SEAC ${ }^{4}$ RS: observations of a modest aerosol enhancement aloft, Atmos. Chem. Phys., 15, 7085-7102, doi:10.5194/acp-15-7085-2015, 2015.

Weber, R. J., Orsini, D., Daun, Y., Lee, Y.-N., Klotz, P. J., and Brechtel, F.: A Particle-into-Liquid Collector for Rapid Measurement of Aerosol Bulk Chemical Composition, Aerosol Sci. Tech., 35, 718-727, 2001.

Ziemba, L. D., Thornhill, K. L., Ferrare, R., Barrick, J., Beyersdorf, A. J., Chen, G., Crumeyrolle, S. N., Hair, J., Hostetler, C., Hudgins, C., Obland, M., Rogers, R., Scarino, A. J., Winstead, E. L., and Anderson, B. E.: Airborne observations of aerosol extinction by in situ and remote-sensing techniques: Evaluation of particle hygroscopicity, Geophys. Res. Lett., 40, 417-422, 2013. 